\title{
Ajuste do modelo fototérmico de estimativa do desenvolvimento e do índice de área foliar de soja ${ }^{1}$
}

\author{
$\overline{\text { Neila T. Toledo }{ }^{2} \text {, Artur G. Muller }{ }^{3} \text {, Jorge L. Berto }{ }^{4} \& \text { Carise E. S. Mallmann }}{ }^{5}$
}

\section{RESU MO}

Visou-se neste estudo, realizar o ajuste do modelo de estimativa do desenvolvimento de populações de soja e da variação do índice de área foliar para a variedade IAS 5. Como fonte de variação na velocidade de desenvolvimento, diferentes épocas de plantio foram utilizadas em experimentos nos anos agrícolas de 2004/2005 (três datas) e 2005/2006 (quatro datas) no IRDeR (Instituto Regional de Desenvolvimento Rural) localizado em Augusto Pestana, RS (28 $27^{\circ} 17^{\prime \prime} \mathrm{Se}$ $53^{\circ} 54^{\prime} 50^{\prime \prime}$ W), nos quais foram identificadas as datas em que ocorreram as principais fases do desenvolvimento da cultura da soja, seguindo a Escala Fenológica de Fehr \& Caviness e estimados o índice de área foliar em quatro momentos: no final do período de instalação da população vegetal (V6); no início do florescimento (R1); início do enchimento de grãos (R5); e no início da maturação (R7). As variáveis meteorológicas temperaturas mínima e máxima diárias foram coletadas. Após o ajuste dos coeficientes genéticos, o modelo foi formatado no programa Stella 5.0. 0 modelo de estimativa do desenvolvimento da soja teve desempenho satisfatório, apresentando estimativas precisas para os dados que 0 determinaram. 0 modelo de estimativa do índice de área foliar apresentou estimativas satisfatórias.

Palavras-chave: modelagem matemática, constante fototérmica, variáveis meteorológicas

\section{Adjustment of the photothermic model to estimate soybean development and leaf area index}

\begin{abstract}
The present study was carried out to adjust the soy population development model and the leaf area index model for the IAS 5 cultivar. Different sowing dates were used in two experiments as source of development variation during 2004/ 2005 (three dates) and 2005/2006 (four dates) in the IRDeR (Instituto Regional de Desenvolvimento Rural) located in Augusto Pestana, in the State of Rio Grande do Sul ( $28^{\circ} 27^{\prime} 17^{\prime \prime} \mathrm{S}$ and $\left.53^{\circ} 54^{\prime} 50^{\prime \prime} \mathrm{W}\right)$. The main crop development phases were identified according to the Feher $\&$ Caviness phenological scale, and the leaf area index was determined in four occasions: at the final period of plant population installation (V6); at the beginning of flowering (R1); at the beginning of seed filling (R5), and at the beginning of maturation (R7). The minimum and maximum temperatures were obtained daily. After the adjustment of the genetic coefficients, the model was formatted using the program Stella 5.0. The soy development model presented a suitable performance, precise estimates from the original data. The leaf area index model also presented satisfactory estimation.
\end{abstract}

Key words: mathematical modeling, photothermic constant, meteorological variables

\footnotetext{
1 Trabalho parcialmente financiado pela FAPERGS e que compõe parte da Dissertação de Mestrado do primeiro autor

2 Mestre em Modelagem Matemática/U NIJUÍ, CEP 98700-000, ljuí, RS. Fone: (55) 3332-0200. E-mail: neila.toledo@yahoo.com.br

3 Embrapa Cerrado. CEP 73310-970, Planaltina, DF. Fone: (61) 3388-9860. E-mail: agmuller@cpac.embrapa.br

4 Departamento de Ciências Agrárias/U NIJUÍ. Fone: (55) 3332-0420. E-mail: jberto@unijui.edu.br

5 Mestre em Modelagem Matemática/UN IJUÍ. Fone: (55) 3332-0200. E-mail: cariseschmit@hotmail.com
} 


\section{INTRODUÇÃO}

A importância do desenvolvimento de modelos no meio científico pode ser ressaltada pelas seguintes razões: os modelos são ferramentas fundamentais para sumarizar o conhecimento científico e auxiliam na tomada de decisão agrícola, ou seja, servem como instrumento para o manejo e elaboração de atividades de planejamento na agricultura (Boote et al., 1996).

Uma ferramenta importante para o estudo do crescimento, desenvolvimento e produtividade de uma cultura, é o uso de modelagem matemática, a qual permite, entre outros, a descrição dos processos envolvidos no sistema e a simulação de situações que auxiliam na tomada de decisões antes do começo do plantio, aproximando-se do melhor resultado possível. Um instrumento significativo para se descrever os processos de crescimento da cultura de soja é a construção de modelos matemáticos que possibilitam o estudo de sistemas reais complexos, o qual exige modelos com integração coerente, banco de dados contendo informações experimentais e edafoclimáticas, além de permitir prever as produtividades de variedades de soja previamente calibradas, em ensaios de campo em alocações em vários ambientes (Costa, 1997).

De acordo com Bassanezi (2002) a modelagem matemática é um processo dinâmico utilizado na obtenção e validação de modelos matemáticos. A modelagem consiste, essencialmente, na arte de transformar situações problemas da realidade em problemas matemáticos cujas soluções devem ser interpretadas na linguagem usual.

Durante o processo de modelagem de um sistema de populações de plantas, diversas simplificações são aceitas, devido à impossibilidade de se considerar todos os detalhes do modelo (Dallacort et al., 2006), sendo utilizados, inicialmente, os fatores mais influentes e cujos processos de interação com o fenômeno a ser modelado são bem conhecidos para, a posteriori, aperfeiçoar o modelo. Um dos fatores imprescindíveis para a modelagem desses sistemas é o efeito da variabilidade climática sobre a produção vegetal, além de aspectos relevantes da interação clima-planta-solo, tanto na forma qualitativa como na quantitativa. Tendo-se como resultado final esperado o auxílio à tomada de decisão, modelos de simulação têm, como dados de saída, as estimativas de rendimento, as datas de ocorrência das fases fenológicas de crescimento das espécies cultivadas, as reservas de umidade do solo, as datas previstas para maturação e colheita. Como base para realização destas estimativas são utilizados modelos de desenvolvimento fenológico, de instalação da área foliar e de interceptação da radiação solar. Há bastante tempo são estudados os efeitos do ambiente e suas interações sobre o desenvolvimento fenológico das plantas, sendo considerados mais importantes os seguintes fatores do meio: temperatura do ar, duração do dia, regime pluviométrico e a ocorrência de frio (Bergamaschi, 2006).

O desenvolvimento normal de uma planta depende de vários fatores, dentre os quais se destacam: a intensidade de radiação solar, relacionada principalmente à atividade fotossintética; a duração da radiação solar, relacionada à duração do dia; à precipitação; temperatura; disponibilidade de água e tratos culturais (Dallacort et al., 2006). De acordo com Sinclair et al. (2005) a duração das fases fenológicos é função das variáveis do meio ambiente, para as quais a planta é sensível em cada fase de seu desenvolvimento; portanto, as avaliações do desenvolvimento fenológico em função das variáveis ambientais específicas, são informações fundamentais para qualquer tentativa de se estabelecer modelos de crescimento, adaptação e produtividade, que considerem a dinâmica do processo (Dallacort et al., 2006).

A duração do dia e a temperatura são necessárias para o desenvolvimento da cultura da soja, em virtude de provocarem mudanças qualitativas ao longo do seu ciclo. As respostas a esses dois fatores não são lineares durante o ciclo de vida da cultura, haja vista que existem subperíodos em que esta é incapaz de perceber esses sinais (Rodrigues et al., 2001).

O objetivo do presente estudo é o ajuste do modelo matemático de estimativa do desenvolvimento de populações de soja e de instalação de superfície foliar.

\section{MATERIAL E MÉTODOS}

\section{Local, clima, solo e genótipo}

Os experimentos foram conduzidos a campo durante os anos agrícolas de 2004/2005 e 2005/2006, instalados no Instituto Regional de Desenvolvimento Rural (IRDeR), localizado no município de Augusto Pestana, no Estado do Rio Grande do Sul; suas coordenadas são: $28^{\circ} 27^{\prime} 17^{\prime \prime}$ S de latitude e $53^{\circ} 54^{\prime} 50^{\prime \prime} \mathrm{W}$ de longitude com a altitude aproximada de 448 m (IPAGRO, 1989).

Conforme a classificação climática de Köeppen, o clima da região é subtropical úmido, de verão quente, do tipo fundamental “cfa”, que é o clima predominante no estado do Rio Grande do Sul e na Região Sul do Brasil; janeiro e fevereiro são os meses mais quentes, enquanto junho e julho são os meses mais frios. A temperatura média nos meses mais quentes é superior a $22^{\circ} \mathrm{C}$ e a dos meses mais frios é inferior a $18^{\circ} \mathrm{C}$ e superior a $3{ }^{\circ} \mathrm{C}$. A precipitação média anual está acima de $1600 \mathrm{~mm}$, sendo bem distribuídos durante todos os meses do ano (Pereira et al., 2002).

Os dados diários de radiação solar incidente $\left(\mathrm{MJ} \mathrm{m}^{-2}\right)$, precipitação $\left(\mathrm{mm} \mathrm{dia}^{-1}\right)$, temperatura mínima $\left({ }^{\circ} \mathrm{C}\right)$, temperatura máxima $\left({ }^{\circ} \mathrm{C}\right)$, termômetro bulbo úmido $9 \mathrm{~h}\left({ }^{\circ} \mathrm{C}\right)$, termômetro bulbo seco $15 \mathrm{~h}\left({ }^{\circ} \mathrm{C}\right)$, termômetro bulbo seco $21 \mathrm{~h}\left({ }^{\circ} \mathrm{C}\right)$, foram medidos na estação agrometeorológica da FEPAGRO, localizada no IRDeR com sede na cidade de Augusto Pestana, RS.

O solo da área experimental é classificado como Latossolo Vermelho Distroférico típico, com as seguintes características: solo profundo, coloração vermelho-escuro, boa drenagem, textura argilosa com predominância de argilominerais 1:1 (EMBRAPA, 1999).

A variedade utilizada nos dois anos agrícolas foi IAS 5 que, conforme Costamilan (2004) apresenta, como principais características: crescimento determinado, altura média de plantas para semeaduras em novembro de $76 \mathrm{~cm}$, teores de óleo de $21,3 \%$ e teor de proteína na semente de $41,5 \%$. 


\section{Delineamento experimental, tratamentos e variáveis}

O delineamento experimental utilizado nos dois anos agrícolas foi o de blocos ao acaso. No ano agrícola de 2004/2005, os tratamentos constaram de três datas de semeadura (19/11/ 04, 12/12/04 e 14/01/05) e no ano agrícola de 2005/2006 os tratamentos tiveram quatro datas de semeadura (12/12/05, 26/12/05, 13/01/06 e 31/01/06) totalizando 7 condições ambientais diferenciadas.

As parcelas foram constituídas de 7 linhas de plantio, espaçadas $0,40 \mathrm{~m}$ entre linhas e $12 \mathrm{~m}$ de comprimento. $\mathrm{O}$ espaçamento entre parcelas foi de $0,50 \mathrm{~m}$ e entre bloco de $1 \mathrm{~m}$. Foram utilizadas, para as amostragens, as 5 linhas centrais com 1,5 m de comprimento sendo as linhas laterais tidas como bordadura.

Acompanhou-se o desenvolvimento fenológico da soja em cada época de semeadura, seguindo-se a Escala Fenológica de Fehr \& Caviness (1977) observando-se os estádios fenológicos em amostras constituídas de 10 plantas por parcela na linha, em períodos variáveis de 7 a 2 dias, dependendo da proximidade em que a cultura se encontrava do estádio de desenvolvimento a ser registrado.

O índice de área foliar foi estimado a partir de amostragens realizadas em quatro momentos: no final do período de instalação da população vegetal (período de crescimento vegetativo V6); no início do florescimento (R1); no início do enchimento de grãos (R5) e no início da maturação (R7). Retiraram-se amostras de $0,4 \mathrm{~m}^{2}$ por parcela, em que foram subamostradas duas plantas por parcela cuja área foliar foi integrada para estimativa da área foliar específica de todas as amostras para estimativa da área foliar da amostra. Com base na área foliar específica estimada e na superfície ocupada pelas plantas, o índice de área foliar foi obtido seguindo a equação:

$$
\mathrm{IAF}=\frac{\mathrm{MSf} \cdot \mathrm{AFE}}{\mathrm{S}}
$$

sendo:

IAF - índice de área foliar

MSf - massa seca de folhas da amostra, g

AFE - área foliar específica, $\mathrm{cm}^{2} \mathrm{~g}^{-1}$

\section{Condução do experimento}

$\mathrm{Na}$ semeadura se realizou o tratamento químico das sementes e, após a sua secagem, efetuou-se a inoculação com Bradyrhizobium japonicum, para aumentar a eficiência de absorção de nitrogênio atmosférico.

Fez-se a adubação de acordo com as recomendações técnicas de adubação e de calagem para os Estados do RS e SC (CQFS, 2004), com base nos resultados da análise de solo. O controle de plantas foi efetuado através da capina manual, enquanto o controle de pragas, como lagarta da soja (Anticársia gemmatalis) e percevejos (Nezara viridula e Piezodorus guildinii) ocorreu quando suas populações se encontravam próximo de atingir o nível de dano econômico.

No segundo ano agrícola foram realizadas semeaduras também em período recomendado para a cultura porém ani- mais silvestres acabaram comendo as plântulas impossibilitando, assim, a realização das avaliações. Realizou-se o desbaste 15 dias após a emergência das plantas, deixando-se as parcelas com a densidade de 300.000 plantas ha-1.

Nos dois anos agrícolas as variáveis avaliadas foram: a identificação das datas nas quais ocorreram as principais fases do desenvolvimento da cultura da soja, conforme a Escala Fenológica de Fehr \& Caviness e o índice de área foliar (IAF) sendo estimados em quatro momentos: no final do período de instalação da população vegetal (período de crescimento vegetativo V6); no início do florescimento (R1); quando é atingido o final do período de enchimento de grãos (R5) e no início da rápida senescência (R7).

\section{Estimativa dos coeficientes para a modelagem}

O modelo que está sendo aferido não contempla o processo de germinação, emergência e início de crescimento vegetativo, haja vista que, durante a primeira fase, a planta ainda está utilizando fontes de energia da semente e o aumento de área foliar não se ajusta à regressão linear. Convencionou-se, portanto, para iniciar a modelagem, que o IAF fosse igual a um; para tanto se identificou o momento em que o fato ocorreu e se estimaram os graus dia acumulado neste momento; para determinação da velocidade de instalação do índice de área foliar foram considerados os subperíodos: V6 até R1, R1 até R5 e R5 até R7.

Os graus-dia acumulados necessários para a instalação da cultura foram determinados para cada ano agrícola através de uma regressão linear da relação entre graus-dias acumulados até V6 e IAF observado. Considerm o IAF de 1 como definidor do final do período de crescimento exponencial do IAF; utilizaram-se as equação lineares para cada ano agrícola a fim de se determinar a soma térmica necessária para atingir esta fase e ser ponto inicial do modelo.

Visando à determinação do acúmulo de dias fototermais ou a taxa de desenvolvimento nos períodos de VE-R1, VE-R5 e VE-R7, estimou-se primeiramente, a duração crítica do dia e aceitando-se aquele que produziu menor desvio padrão na estimativa da constante térmica para os sete ambientes analisados. Para tanto foram considerados duração crítica do dia ou ótima, valores entre 12 h e 16,5 h, para cada um dos sete ambientes estudados. Os resultados encontrados foram submetidos a uma análise de regressão entre a duração do dia e o desvio padrão, e definição do ponto de mínimo para cada experimento. O valor de temperatura no ponto de mínimo corresponde à duração ótima do dia; a partir deste valor foi calculado o acúmulo de dias fototermais.

\section{Descrição do modelo matemático}

O modelo a ser utilizado neste trabalho se baseia em relações ecofisiológicas e é calibrado a partir de referências bibliográficas e de resultados experimentais, em que foram acompanhados as condições meteorológicas e o desenvolvimento da cultura.

O IAF estimado pelo submodelo linear segmentado foi calculado a partir da Eq. 2 que traz o IAF em função dos grausdia acumulados e do estádio de desenvolvimento da cultura, cujo índice é dependente dos dias fototermais acumulados. 
$\mathrm{IAF}_{\mathrm{i}}=\mathrm{GD}_{\mathrm{i}} \cdot \mathrm{c} \cdot \mathrm{a}_{\mathrm{n}}$

em que

$$
\begin{aligned}
\mathrm{IAF}_{\mathrm{i}} \text { - } & \text { IAF no i-ésimo dia } \\
\mathrm{n}- & \text { enésimo período do ciclo cuja velocidade de } \\
& \text { instalação do índice de área foliar se pressupõe } \\
& \text { ser constante } \\
\mathrm{GD}_{\mathrm{i}}- & \text { são os graus-dia acumulados até o i-ésimo dia, } \\
& { }^{\circ} \mathrm{C} \text { dia-1 } \\
\mathrm{C}- & \text { máxima velocidade de instalação da cultura } \\
\mathrm{a}_{\mathrm{n}}- & \text { coeficiente para o n-ésimo período tabelado, } \\
& \text { neste trabalho, em função da constante fototér- } \\
& \text { mica }
\end{aligned}
$$

De início, o índice de área foliar da soja tem um crescimento exponencial, até que as reservas da semente sejam consumidas e o recurso energético para crescimento seja oriundo só da fotossíntese; em seguida ocorre um aumento linear até o início do florescimento mas não há falta de disponibilidade dos fatores de crescimento; este processo é proporcional ao acúmulo de graus-dia, ou seja, a instalação da área foliar depende do acúmulo dos graus-dia; a este período corresponde o primeiro segmento do modelo de simulação do IAF.

Com o início da formação de vagens em R1, acontece redução na velocidade de crescimento do índice de área foliar pois a planta começa a utilizar os seus fotoassimilados para a formação de novos componentes, as vagens e os grãos; a este período corresponde o segundo segmento do modelo. Os valores de IAF no início da formação de grãos, em R5, tendem a se estabilizar ou se manterem constantes até o começo da maturação fisiológica da planta no estádio reprodutivo R7; a cujo período corresponde o terceiro segmento do modelo. Após a maturação fisiológica ocorre a rápida senescência das folhas e caules, proporcionando a redução nos valores de IAF.

Segundo Francisco et al. (2007), o valor do IAF varia de acordo com o clima, o estádio de desenvolvimento da planta e a estação do ano, sendo maior para maiores intensidades luminosas e quando a proporção de radiação direta na radiação incidente aumenta, além de ser dependente da arquitetura e composição botânica/morfológica da planta.

No modelo proposto a velocidade de instalação do índice de área foliar é definida pela quantidade de GD disponível por dia e pelo estádio fenológico em que a planta se encontra e que é estimada a partir do índice de dias fototermais e que definirá o valor do coeficiente $a_{n}$.

O crescimento vegetativo é pequeno ou nulo, em temperaturas menores ou iguais a $10^{\circ} \mathrm{C}$; temperaturas acima de $40^{\circ} \mathrm{C}$ terão efeito adverso na taxa de crescimento, provocando estragos na floração e diminuição da capacidade de retenção dos legumes (EMBRAPA, 1998). O florescimento atrasa quando a temperatura permanece inferior a $23^{\circ} \mathrm{C}$ (Mota, 1993) e não ocorre quando em temperaturas inferiores a $13{ }^{\circ} \mathrm{C}$ (Miranda et al., 1981; EMBRAPA, 1998). As temperaturas baixas no período de maturação da soja, associadas à alta umidade, podem provocar atraso na data de colheita e na ocorrência de retenção foliar (EMBRAPA, 1998).

A estimativa dos graus-dia acumulados $\left({ }^{\circ} \mathrm{C} \operatorname{dia}^{-1}\right)$ após a emergência foi realizada a partir da equação:

$$
\mathrm{GDA}=\sum_{\mathrm{i}=1}^{\mathrm{n}}\left[\left(\frac{\text { Tmáx }_{\mathrm{i}}-\text { Tmín }_{\mathrm{i}}}{2}\right)-\mathrm{Tb}\right]
$$

em que

GDA - total de graus-dia acumulados ao longo da fase ou ciclo

n - número de dias da fase, ciclo ou o número de dias até a maturação fisiológica

Tmáx $\mathrm{i}_{\mathrm{i}}$ - temperatura máxima registrada no dia i, ${ }^{\circ} \mathrm{C}$

$\mathrm{T}^{\mathrm{T} i ́ n} \mathrm{i}_{\mathrm{i}}$ - temperatura mínima registrada no dia i, ${ }^{\circ} \mathrm{C}$

$\mathrm{Tb}$ - temperatura base da cultura da soja, de $14{ }^{\circ} \mathrm{C}$, de acordo com Pereira et al. (2002)

A constante fototérmica (CFT), apresentada na Eq. 4, estima o momento em que a soja atinge outro estádio fenológico, expressa pelo somatório do índice de dias fototermais no dia i ao longo do ciclo da cultura (n). Para a utilização desta equação é necessário o conhecimento prévio da constante fototérmica do genótipo, o que é obtido a partir do acompanhamento do desenvolvimento da cultura e da temperatura e fotoperíodo em diferentes ambientes.

$$
\mathrm{CFT}=\sum_{\mathrm{i}=1}^{\mathrm{n}} \mathrm{R}(\mathrm{i})
$$

O índice de dias fototermais R(i) define a velocidade de desenvolvimento somente durante o estádio reprodutivo (entre floração e maturação fisiológica) porém este advém de um efeito cumulativo desde a emergência e, devido a isto, é estimado a partir da emergência da plântula considerandose a duração do dia e a temperatura do ar; já no estádio vegetativo o desenvolvimento da soja só será influenciado pela temperatura do ar. A seguir é apresentada a equação utilizada para a determinação da R(i):

$$
\mathrm{R}(\mathrm{i})=\operatorname{Fr}(\mathrm{T}) \cdot \mathrm{F}(\mathrm{N})
$$

em que:

$\mathrm{R}(\mathrm{i})$ - índice de dias fototermais no dia i

$\operatorname{Fr}(\mathrm{T})$ - função da temperatura

$\mathrm{F}(\mathrm{N})$ - função da duração do dia

A função da temperatura é expressa pela equação:

$$
\operatorname{Fr}(T)=\frac{\left(\bar{T}_{i}-\text { Tmín }\right)}{(\text { Tot }- \text { Tmín })}
$$

em que

$\operatorname{Fr}(\mathrm{T})$ - função da temperatura

$\overline{\mathrm{T}}_{\mathrm{i}}$ - temperatura média diária no i-éssimo dia, ${ }^{\circ} \mathrm{C}$

Rmín - temperatura mínima diária, segundo Boote et al. (1993) como sendo $6^{\circ} \mathrm{C}$

Tot - temperatura ótima diária, segundo Boote et al. (1993) como sendo $30^{\circ} \mathrm{C}$

Obteve-se a função da duração do dia através da equação:

$$
\mathrm{F}(\mathrm{N})=\frac{\left(\mathrm{CN}_{\mathrm{i}}-\mathrm{Nmín}\right)}{(\text { Not }- \text { Nmín })}
$$

em que:

R. Bras. Eng. Agríc. Ambiental, v.14, n.3, p.288-295, 2010. 
$\mathrm{F}(\mathrm{N})$ - função da duração do dia

$\mathrm{CN}_{\mathrm{i}}$ - comprimento da noite, $\mathrm{h}$

Nmín - comprimento mínimo da noite, h, de acordo com Boote et al. (1991) assume o valor de $5 \mathrm{~h}$

Not - comprimento ótimo ou crítico da noite (h), determinando-se neste trabalho o valor de 18,8 h

A duração da noite $(\mathrm{CN})$ tem importância devido à capacidade de alguns organismos em captarem comprimentos de onda que continuam incidindo durante a noite e, através de estímulo a produção hormonal, controlarem a velocidade de desenvolvimento. A duração da noite foi obtida através da equação:

$$
\mathrm{CN}_{\mathrm{i}}=24-\mathrm{CD}_{\mathrm{i}}
$$

em que:

24 - coeficiente que expressa a duração do dia, $\mathrm{h}$

$\mathrm{CD}_{\mathrm{i}}$ - duração do dia no i-ésimo dia, $\mathrm{h}$

A duração do dia (CD), que é o número de horas entre o nascer e o pôr-do-sol, é o fator mais importante na determinação da proporção relativa entre os períodos vegetativo e reprodutivo da soja, influenciando, também, o período de florescimento até a formação da vagem e a maturação. A duração do dia no í-ésimo dia é estimada pela equação a seguir:

$$
\mathrm{CD}_{\mathrm{i}}=\frac{\left(\mathrm{Hp}_{\mathrm{i}} \cdot 2\right)}{15}
$$

em que o $\mathrm{Hp}_{\mathrm{i}}$ é o ângulo horário correspondente ao pôr-dosol (graus e décimos) no dia i e foi calculado pela equação:

$$
\mathrm{Hp}_{\mathrm{i}}=\operatorname{arcos}\left(-\operatorname{tg} \gamma \cdot \operatorname{tg} \sigma_{\mathrm{i}}\right)
$$

em que:

$\gamma$ - latitude do local, que na área experimental é de $-28^{\circ}$

$\sigma_{\mathrm{i}}-$ declinação do sol (graus e décimos) no i-ésimo dia

A declinação do sol ( $\sigma$ ) foi calculada pela equação:

$$
\sigma_{\mathrm{i}}=23,45 \cdot \operatorname{sen}\left[\frac{360}{365} \cdot(284+\mathrm{Dj})\right]
$$

em que: $\mathrm{Dj}$ - dia Juliano (número de ordem a partir de $1^{\circ}$ de janeiro)

\section{RESULTADOS E DISCUSSÃO}

A aparição de novas folhas define a passagem de fase fenológica durante o período vegetativo, processo este definido pelo acúmulo de graus-dia, ou seja, apenas influenciado pela temperatura. Nas Tabelas 1 e 2 se apresentam os valores acumulados de graus-dia e índice fototérmico para cada estádio de desenvolvimento observado nas diferentes épocas de plantio. A velocidade de instalação das cinco primeiras folhas trifolioladas (V6) teve grande vari- ação entre as épocas e experimentos. A qualidade inferior das sementes no segundo experimento pode ser identificada como um dos fatores responsáveis pelos elevados valores de acúmulo de graus dia em que o estádio V6 foi atingido neste experimento, ou seja, demorou mais para atingir esta fase fenológica.

Tabela 1. Graus-dias acumulados nos diferentes períodos de desenvolvimento da soja da variedade IAS 5, para as datas de semeadura utilizadas nos experimentos dos anos agrícolas de 2004/ 2005 e 2005/2006, em Augusto Pestana, RS

\begin{tabular}{crrrrrrrr}
\hline \multirow{2}{*}{ Período } & Ano agrícola de 2004/2005 & & \multicolumn{3}{c}{ Ano agrícola de 2005/2006 } \\
\cline { 2 - 3 } \cline { 6 - 8 } VE - V6 & $\mathbf{2 9} / 11 / 04$ & $\mathbf{1 2 / 1 2 / 0 4}$ & $\mathbf{1 4 / 0 1 / 0 5}$ & & $\mathbf{1 2 / 1 2 / 0 5}$ & $\mathbf{2 6 / 1 2 / 0 5}$ & $\mathbf{1 3 / 0 1 / 0 6}$ & $\mathbf{3 1 / 0 1 / 0 6}$ \\
VE - R1 & 582,6 & 522,4 & 420,0 & & 592,6 & 583,9 & 453 & 459,5 \\
VE - R5 & 774,9 & 703,4 & 591,8 & 837,0 & 772,4 & 681 & 614,0 \\
VE - R7 & 1228,2 & 1060,3 & 811,3 & & 1097,8 & 1012,6 & 826 & 668,7 \\
\hline
\end{tabular}

O período da emergência até V6 ocorre em menor quantidade de graus dia para a data de semeadura do dia 14/01/2005, no primeiro experimento, e na data de semeadura do dia 13/01/2006, no segundo experimento, em razão, provavelmente, da condição de umidade do solo, pois as irrigações sempre foram realizadas em todo o experimento, buscando-se evitar deficiências nas parcelas mais adiantadas, o que pode ter causado um excesso hídrico na cultura semeada mais tardiamente, sobretudo durante os períodos iniciais da cultura, quando o consumo hídrico é menor, porém foram necessárias irrigações após a emergência dessas duas datas de plantio para suprir as parcelas com a cultura mais adiantada.

A sensibilidade fotoperiódica varia com o genótipo da soja. Cada cultivar possui necessidades de acúmulo de índice fototérmico para atingir determinado estádio reprodutivo, embora a sua duração crítica, ou ótima, do dia crítico também possa ser variável. A estimativa da duração crítica do dia para a variedade IAS 5 foi obtida a partir dos resultados apresentados na Figura 1A e B, que apresentam a relação entre o desvio padrão do índice fototérmico, necessário para atingir o florescimento, calculado para os ambientes e a duração do dia em cada experimento. Os ajustes polinomiais da relação entre essas duas grandezas resultaram significativas para equações de segundo grau, para ambos os experimentos; referidas equações possibilitaram o cálculo do ponto de mínimo, estimado em 18,7 para o primeiro ano agrícola e 18,8 para o segundo ano, cuja média, de 18,8 h, originou a duração do dia crítico ou ótimo do modelo; este valor é bem superior em relação ao obtido por Dallacort et al. (2006), que determinaram como comprimento crítico do dia para a região de Palotina, no Paraná 12,83 h, e que acima deste valor o desenvolvimento reprodutivo não é afetado. Apesar desta comparação apresentar confundimento do efeito do ambiente e da variedade a diferença está bem acima do esperado e permite a suposição de que outras condições ambientais como o grau de nebulosidade e a característica espectral da radiação possam alterar este coeficiente. 


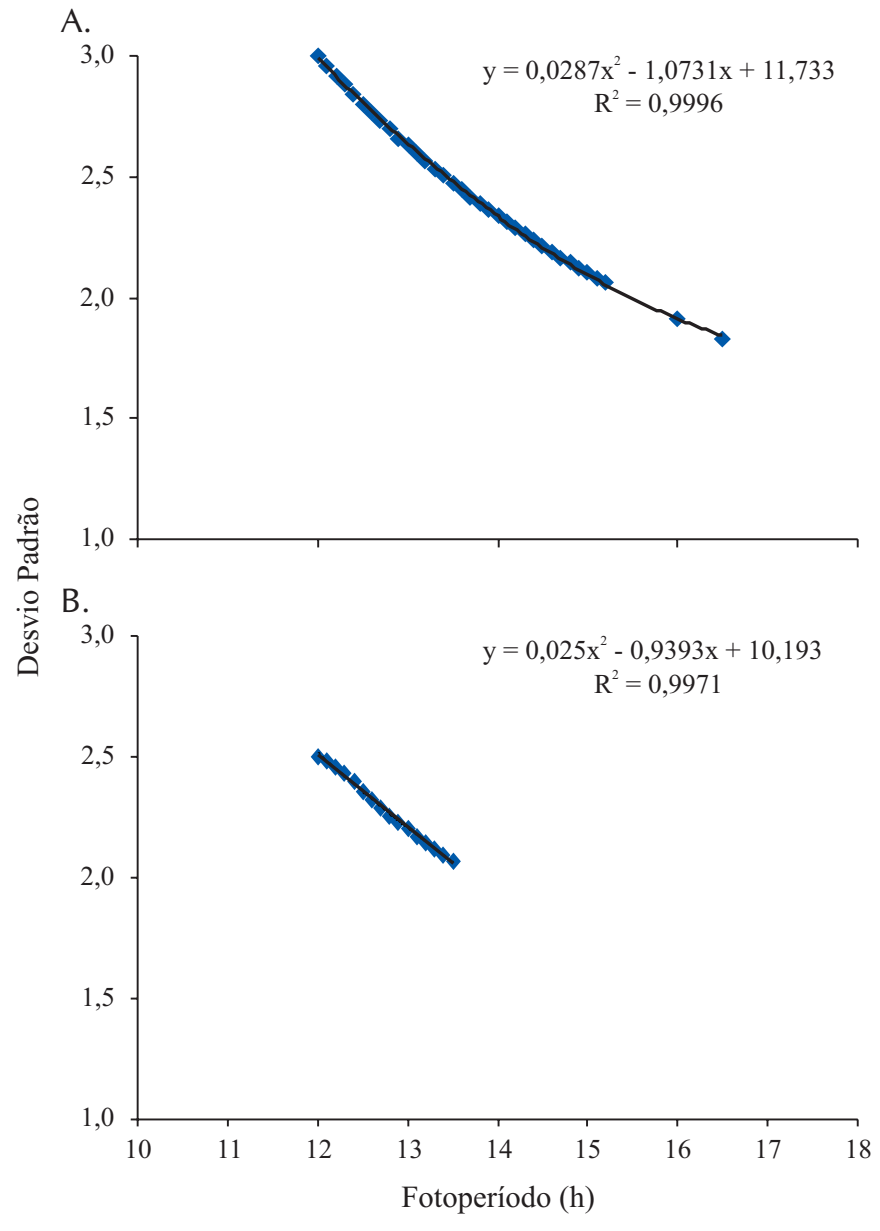

Figura 1. Relação entre duração do dia (h) e desvio padrão do somatório do Índice Fototérmico da VE - R1 do ano agrícola de 2004/2005 (A) e 2005/2006 (B)

Ocorreu diferença entre os valores da duração do dia crítico estimado neste trabalho em relação às referências produzidas por outros autores, tais valores deverão ser validados com novos experimentos, pois as variações entre cultivares devem originar parcela desta variação.

Com base na duração do dia crítico estimado neste trabalho, se estimaram os acúmulos de dias fototermais ocorridos entre a emergência das plântulas e o início dos estádios fenológicos R1, R5 e R7, para todas as datas de semeadura adotadas. O período que apresentou maior coeficiente de variação foi o da emergência até R5 e R7, como previsto, haja vista que suas fases finais são de identificação mais difícil, incluindo-se um erro neste procedimento, porém os valores de coeficiente de variação foram baixos e os valores mais baixos obtidos na última semeadura do primeiro ano de experimento não são estatisticamente discrepantes dos demais.

A média aritmética entre os acúmulos de dias fototermais apresentados na Tabela 2, nos tratamentos dos dois experimentos definiu a constante fototérmica para atingir os estádios fenológicos encontrando-se, para R1, R5 e R7, os respectivos valores: 16,48; 24,24 e 36,26.

Apesar de referências obtidas por outros autores, como Dallacort et al. (2006), que encontraram o valor de 27 dias fototermais como necessidade de dias fototermais para o período de VE-R1, estar distante do obtido neste artigo, ambos podem apresentar eficiência na estimativa da data de ocorrência de cada estádio fenológico, pois são obtidos a partir de diferentes coeficientes de temperatura base e duração crítica do dia.

Apesar da comparação das datas observadas e estimadas apresentadas na Tabela 3 não servir para validação do modelo, uma vez que não se trata de dados independentes dos utilizados para sua calibração, esta permite verificar a inexistência de alguma discrepância mais séria. O maior desvio do valor estimado em relação ao observado ocorreu no estádio R7 na data de plantio de 13/01/2006; nas outras observações os erros de estimativa são de, no máximo, um dia. O estádio R7 pode ser adiantado quando a intensidade de radiação solar é baixa e acelera a queda das folhas e, consequentemente, a maturação das vagens, isto é, o aumento do erro nesta última fase é esperado quando o referido fenômeno ocorre.

Tabela 2. Índices que originaram os valores médios de acúmulo de dias fototermais para cultura da soja da variedade IAS 5, em dois anos agrícolas

\begin{tabular}{|c|c|c|c|c|c|c|c|c|c|}
\hline \multirow{2}{*}{ Período } & \multicolumn{3}{|c|}{ Ano Agrícola de 2004/2005 } & \multicolumn{4}{|c|}{ Ano Agrícola de 2005/2006 } & \multirow{2}{*}{ Média } & \multirow{2}{*}{ CV (\%) } \\
\hline & $19 / 11 / 04$ & $12 / 12 / 04$ & $14 / 01 / 05$ & $12 / 12 / 05$ & $26 / 12 / 06$ & $13 / 01 / 06$ & $31 / 01 / 06$ & & \\
\hline VE - R1 & 17,35 & 16,37 & 14,36 & 16,87 & 16,81 & 16,92 & 16,69 & 16,48 & 5,95 \\
\hline VE - R5 & 23,76 & 23,15 & 20,92 & 25,70 & 23,93 & 27,01 & 25,24 & 24,24 & 8,13 \\
\hline VE - R7 & 40,61 & 36,76 & 33,15 & 36,02 & 34,98 & 36,82 & 35,51 & 36,26 & 6,31 \\
\hline
\end{tabular}

Tabela 3. Datas observadas e estimadas dos estádios fenológicos V6, R1, R5 e R7 em soja da variedade IAS 5, em datas de semeadura nos experimentos de 2004/2005 e 2005/2006, em Augusto Pestana, RS

\begin{tabular}{|c|c|c|c|c|c|c|c|c|}
\hline \multirow{2}{*}{$\begin{array}{c}\text { Data de } \\
\text { semeadura }\end{array}$} & \multicolumn{2}{|c|}{ V6 } & \multicolumn{2}{|c|}{ R1 } & \multicolumn{2}{|c|}{ R5 } & \multicolumn{2}{|c|}{ R7 } \\
\hline & observada & estimada & observada & estimada & observada & estimada & observada & estimada \\
\hline $19 / 11 / 04$ & 28/12/04 & 27/12/05 & 26/01/05 & $26 / 01 / 05$ & $16 / 02 / 05$ & $16 / 02 / 05$ & 03/04/05 & $03 / 04 / 05$ \\
\hline $12 / 12 / 04$ & $15 / 01 / 05$ & $16 / 01 / 05$ & $14 / 02 / 05$ & $15 / 02 / 05$ & 05/03/05 & $06 / 03 / 05$ & $11 / 04 / 05$ & $12 / 04 / 05$ \\
\hline $14 / 01 / 06$ & 21/02/05 & $22 / 02 / 05$ & 06/03/05 & 07/03/05 & 24/03/05 & $25 / 03 / 05$ & $01 / 05 / 05$ & 02/05/05 \\
\hline $12 / 12 / 05$ & 16/01/06 & 17/01/06 & $11 / 02 / 06$ & 12/02/06 & 10/03/06 & 10/03/06 & 07/04/06 & 07/04/06 \\
\hline 26/12/05 & $31 / 01 / 06$ & $31 / 01 / 06$ & 24/02/06 & $24 / 02 / 06$ & $17 / 03 / 06$ & $17 / 03 / 06$ & 19/04/06 & $18 / 04 / 06$ \\
\hline $13 / 01 / 06$ & $24 / 02 / 06$ & $24 / 02 / 06$ & 08/03/06 & 08/03/06 & 07/04/06 & 07/04/06 & $17 / 05 / 06$ & $23 / 05 / 06$ \\
\hline $31 / 01 / 06$ & $10 / 03 / 06$ & $10 / 03 / 06$ & 29/03/06 & 29/03/06 & 25/04/06 & $25 / 04 / 06$ & 07/06/06 & $07 / 06 / 06$ \\
\hline
\end{tabular}


Visando ao ajuste do submodelo linear segmentado do IAF, se definiram o início e o término dos segmentos. $\mathrm{O}$ início do modelo ocorreu quando a cultura superou a fase de aumento exponencial de IAF e iniciou a fase de maior crescimento linear; esta fase ocorre logo após a instalação da cultura e foi preestabelecido como sendo de IAF unitário e, para atingilos, foi necessário, em média, a somatória de $215{ }^{\circ} \mathrm{C} \mathrm{dia}{ }^{-1}$ no ano agrícola de $2004 / 2005$ e de $270{ }^{\circ} \mathrm{C} \mathrm{dia}{ }^{-1}$ no ano de $2005 /$ 2006. O valor do primeiro ano foi aceito para compor o modelo, em que o valor encontrado para o ano agrícola de 2005/ 2006 foi maior devido ao baixo vigor da semente utilizada; então, este coeficiente não deve ser utilizado como referência para a cultura.

As necessidades de acúmulo de dias fototermais para início dos estádios fenológicos de R1, R5 e R7, determinados acima, são os momentos em que ocorrem as intersecções entre os segmentos do submodelo de estimativa do IAF.

A velocidade máxima de aumento do IAF estimada foi de 0,0146, utilizado no modelo. No subperíodo de V6 até R1, de rápido crescimento foliar, o parâmetro $\left(\mathrm{a}_{\mathrm{n}}\right)$ utilizado na Eq. 2 é 1, pois corresponde ao período de rápido aumento do IAF e aos valores observados. No segundo subperíodo (entre R1 até R5) o valor de $a_{n}$ encontrado foi de 0,342466 e, no subperíodo de R5 até R7, o valor deste coeficiente foi zero, visto que o crescimento foliar nesta fase é desprezível; para o subperíodo de R1 até R5, o foi definido a partir do quociente entre a velocidade de instalação do IAF entre R1 e R5, obtendo-se o valor de 0,005 e da máxima velocidade de instalação do IAF de 0,0146. Obteve-se o valor do numerador pela média aritmética da relação entre IAF e grausdia no subperíodo de R1 até R5, para cada época de plantio dos dois anos agrícolas (2004/2005 e 2005/2006).

A Figura 2A e B ilustra os resultados das estimativas de IAF pelo submodelo linear segmentado ajustado e os valores encontrados no campo experimental.

As diferenças entre os valores de IAF estimado (através do modelo matemático) e o IAF observado (através de dados experimentais) podem ser visualizadas na Figura 2A, em que a evolução dessas duas grandezas está sendo apresentada em função das variações do acúmulo de dias fototermais para as diferentes datas de semeadura em cada ano agrícola. Observa-se que alguns valores medidos estão distantes do estimado e apresentam pequenas incoerências no seu comportamento; por exemplo, no caso da quarta data de plantio do experimento, de 2005/06, não ocorreu aumento de IAF entre R1 e R5, o que não se verifica quando a cultura está bem suprida de água e nutrientes. O comportamento da curva estimada apresenta algumas discrepâncias em relação às observações de campo, sobretudo quanto às diferenças de IAFmáx estimada e observada que podem ser afetadas por outro fator, como a radiação incidente, passível de ser incorporada ao modelo, a partir de novos trabalhos.

Apesar das imperfeições diagnosticadas, o comportamento da curva de IAF estimada em função dos graus dia acumulados em cada período de desenvolvimento estimado pela soma fototérmica, está de acordo com as variações observadas de IAF.
A.

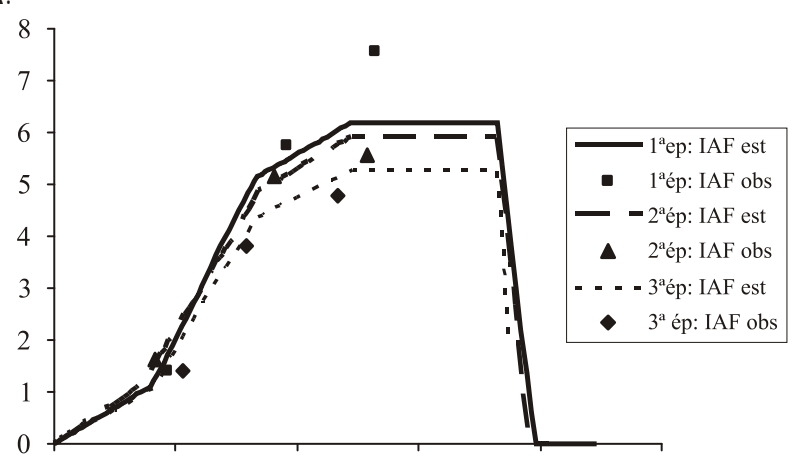

B.

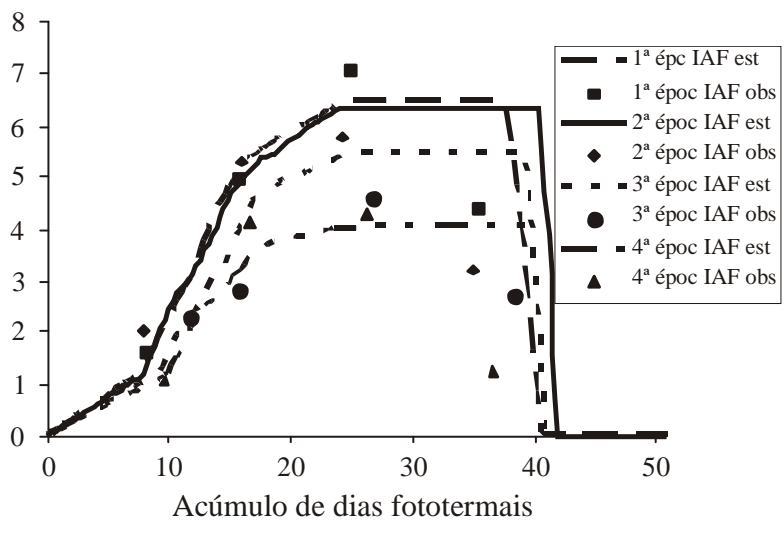

Figura 2. Relação entre Indice de área foliar (IAF) estimado e IAF observado com 0 acúmulo de dias fototermais no experimento de 2004/2005 (A) e 2005/2006 (B), em Augusto Pestana, RS

\section{CONCLUSÕES}

1. O modelo de estimativa do desenvolvimento da soja, baseado na temperatura, na duração do dia e no coeficiente calibrado para duração ótima do dia, teve desempenho eficaz, apresentando estimativas precisas para os dados que o determinaram.

2. O submodelo linear segmentado do IAF, determinado pelos graus-dia acumulados e pelas variações do acúmulo de dias fototermais em cada um dos estádios fenológicos estudados neste trabalho, mostrou-se coerente com os dados observados, obtidos experimentalmente.

\section{LITERATURA CITADA}

Bassanezi, R. C. Ensino-aprendizagem com modelagem matemática: Uma nova estratégia. São Paulo: Contexto, 2002. 389p.

Bergamaschi, H. Fenologia. <http://www.google.com.br/ search?hl=ptBR\&q=fenologia+homero\&meta=>. 18 Out. 2006.

Boote, K. J.; Grimm, S. S.; Jones, J. W.; Hesketh, J. D. Parameter estimation for predicting flowering date of soybean cultivars. Crop Science, v.33, p.137-144, 1993.

Boote, K. J.; Jagtap, S. S.; Jones, J. W.; Mishoe, J. W. Soybean developemnt. In: Hanks, J.; Ritchie, J. T. Modeling plant and soil systems. Madison: Agronomy, 1991. 545p. 
Boote, K. J.; Jones, J. W. Pickerning, N. B. Potencial uses and limitions of crop models. Agronomy Journal, v.88, p.695-697, 1996.

Costa, L. C. Modelagem e simulação em agrometeorologia. In. Congresso Brasileiro de Agrometeorologia, 10, 1997, Piracicaba. Anais... Piracicaba: SBA, 1997, CD-Rom.

Costamilan, L. M.; Bertagnoli, P. F. (org). Indicações técnicas para a cultura da soja no Rio Grande do Sul e em Santa Catarina: 2004/2005. Passo Fundo: Embrapa-CNPT, 2004. 172p.

CQFS - Comissão de Química e Fertilidade do Solo. Manual de adubação e de calagem para os estados do RS e SC. 10.ed. Porto Alegre: SBCS - Núcleo Regional Sul, 2004. 394p.

Dallacort, R.; Freitas, P. S. L. de; Faria, R. T. de; Gonsalves, A. C. A.; Rezende R.; Bertonha, A. Utilização do modelo cropgrosoybean na determinação das melhores épocas de semeadura da cultura da soja, na região de Palotina, estado do Paraná. Acta Scientiarum, v.28, n.04, p.583-589, 2006.

EMBRAPA - Empresa Brasileira de Pesquisa Agropecuária. Centro de Pesquisa Agropecuária - Sistemas de produção. Tecnologia de produção da soja, estado do Paraná. Londrina: EMBRAPA, 1998. 195p. Informações Técnicas

EMBRAPA - Empresa Brasileira de Pesquisa Agropecuária. Sistema brasileiro de classificação de solos. Rio de Janeiro, Embrapa Solos, 1999. 306p.

Fehr, W. R.; Caviness, C. E. Stages of soybean development. Ames: University of Sciense and Technology, 1977. 11p. Special Report 80
Francisco, E. A. B.; Câmara, G. M. de S.; Segatelli C. R. Estado nutricional e produção do capim pé-de-galinha e da soja cultivada em sucessão em sistema antecipado de adubação. Bragantia, v.66, p.259-266, 2007.

IPAGRO. Atlas agroclimático do Estado do Rio Grande do Sul. Porto Alegre: IPAGRO, 1989, v.1.

Miranda, M. A. C.; Myasaka, S.; Mascarenhas, H. A. A. Melhoramento da soja no Estado de São Paulo. In: Myasaka, S.; Medina, J. C. (ed.). A soja no Brasil. Campinas: Fundação Cargill, 1981. p.73-108.

Mota, F. S. Condições climáticas e produção de soja no sul do Brasil. In: Vernetti, F. J. (ed.). Soja: Planta, clima, pragas, moléstias e invasoras. Campinas: Fundação Cargil, 1983. p.91-126.

Pereira, A. R.; Angelocci, L. R.; Sentelhas, P. C. Agrometeorologia: Fundamentos e aplicações práticas. Guaíba: Agropecuária, 2002. 478p.

Rodrigues, O.; Didonet, A. D.; Lhamby, J. C. B.; Bertagnolli, P. F.; Luz, J. S. Resposta quantitativa do florescimento da soja à temperatura e ao fotoperíodo. Pesquisa Agropecuária Brasileira, v.36, n.3, p.431-437, 2001.

Sinclair, T. R.; Neumaier, N.; Farias, J. R. B.; Nepomuceno, A. L. Comparison of vegetable development in soybean cultivars for low-latitude environments. Field Crops Research, v.92, p.53-59, 2005. 